\title{
FÓRUM
}

Submetido 30.06.2019. Aprovado 17.03.2020

Avaliado pelo sistema double blind review. Editores convidados: Diego M. Coraiola, Amon Barros, Mairi Maclean e Willian M. Foster Versão original

DOI: http://dx.doi.org/10.1590/So034-759020210106

\section{INSCRIÇÕES CONTÁBEIS PARA O EXERCÍCIO DO PODER ORGANIZACIONAL: O CASO DO FUNDO DE EMANCIPAÇÃO DE ESCRAVOS NO BRASIL}

\author{
Accounting inscriptions for the exercise of organizational power: The case of \\ the slave emancipation fund in Brazil \\ Inscripciones contables para el ejercicio del poder de la organización: El caso \\ del fondo de emancipación de esclavos en Brasil
}

\begin{abstract}
RESUMO
O objetivo desta pesquisa é analisar como o poder organizacional pode ser exercido sobre populações específicas por meio das inscrições contábeis. A metodologia de pesquisa é baseada em um estudo de caso e pesquisa de arquivo. 0 estudo de caso do Fundo de Emancipação teve como base de análise a legislação, documentos de arquivo e notícias de jornais. Quanto à abordagem adotada, este artigo utiliza o conceito da governamentalidade para a condução de uma análise interpretativa dos dados. Os resultados demonstram que o uso das inscrições contábeis permitiu o controle territorial e da arrecadação de quantias para a constituição das quotas municipais do Fundo de Emancipação, a supervisão dos senhores, e estabeleceu critérios de seleção para a alforria de escravos considerados "dignos de liberdade", mantendo, dessa forma, o controle sobre a transição gradual do trabalho escravo para o trabalho assalariado.

PALAVRAS-CHAVE | Inscrições contábeis, escravo, governamentalidade, Fundo de Emancipação, História da contabilidade.

\section{ABSTRACT}

This research aims to analyze how organizational power can be exercised over specific populations through accounting inscriptions. This aim has been achieved by using a methodology based on a case study and archive research. The case study of the national emancipation fund was based on the analysis of legislation, archival documents, and newspapers. The concept of governmentality has been used to conduct an interpretative data analysis. The results demonstrate that the accounting inscriptions allowed territorial control and collection of amounts for constitution of municipal emancipation fund, supervision of the slavers owners, and establishment of selection criteria for the manumission of slaves considered "worthy of freedom. "In this way, the imperial state maintained control over the gradual transition from slavery to wage labor.
\end{abstract}

KEYWORDS / Accounting inscriptions, slave, governmentality, Emancipation Fund, Accounting history

\section{RESUMEN}

El presente estudio analiza cómo el poder organizacional puede ejercerse sobre las poblaciones específicas a través de inscripciones contables. La metodología de investigación se basa en un estudio de caso y una investigación de archivo. El estudio de caso del fondo de emancipación se basó en el análisis de la legislación, documentos de archivo y noticias periodísticas. Este artículo utiliza el concepto de la gubernamentalidad en la conducción de un análisis interpretativo de los datos. Los resultados demuestran que el uso de las inscripciones contables permitió el control de la recaudación de cantidades para la constitución de las cuotas municipales del fondo de emancipación, la supervisión de los señores, el control territorial y de la selección para la manumisión de esclavos considerados "dignos de libertad", manteniendo así el control sobre la transición gradual del trabajo esclavo al trabajo asalariado.

PALABRAS CLAVE / Inscripciones contables, esclavo, gubernamentalidad, Fondo de Emancipación, Historia contable. 


\section{INTRODUÇÃO}

Em sequência de sua capacidade de movimentação, as inscrições contábeis são visualizadas como expressões materiais capazes de apoiar o gerenciamento de eventos e populações (Robson, 1992). Alguns estudiosos que pesquisam sobre as inscrições contábeis têm demonstrado interesse no seu uso para a produção de fatos (Ezzamel, Lilley, \& Willmott, 2004), nas condições de sua atuação a distância (Robson, 1992) e no seu poder de criação e promoção da "ordem" na sociedade (Ezzamel, 2009). Esta pesquisa atende às chamadas de Ezzamel et al. (2004), Robson (1992) e Ezzamel (2009) sobre a elaboração de novas pesquisas referentes às inscrições contábeis e sobre seu potencial para auxiliar o estabelecimento da ordem social. Este estudo também contribui com a literatura existente sobre o uso da contabilidade (e suas expressões) para o controle da sociedade e a pesquisa contábil interpretativa sobre as inter-relações da contabilidade com o Estado (Carmona, 2017).

O foco desta pesquisa é o Fundo de Emancipação de escravos, tema esse que tem sido desenvolvido por historiadores não contadores como Dauwe (2004), Neves (2014) e Santana (2018), por exemplo. Dauwe tem como objetivo compreender a estrutura do Fundo de Emancipação, tanto como instrumento jurídico quanto administrativo. Neves procura reavaliar a participação do escravo no processo de construção de sua liberdade. Santana investiga como ocorreu a trajetória da indenização aos senhores e a falta de reparação aos libertos nas emancipações. Nenhum dos autores buscou compreender como o poder estatal foi exercido sobre populações específicas por meio das inscrições contábeis que acompanham o programa de governo (Robson, 1992), no caso, o Fundo de Emancipação de escravos.

Este artigo baseia-se no estudo dos citados historiadores, investigando o uso das inscrições contábeis para o controle dos escravos e dos seus senhores. A instituição do Fundo de Emancipação permitiu o estabelecimento de mecanismos para combater o domínio senhorial sobre os escravos e a construção da liberdade escrava de maneira gradual (Neves, 2014). Para a sua operacionalização, o Fundo de Emancipação exigiu o uso de mecanismos de controle, como a contabilidade e suas expressões.

Este artigo traz novos conhecimentos para pesquisas anteriores. Neu (2000a, 2000b) apresenta a contabilidade e suas expressões como tecnologia do governo útil para tornar governável uma população específica. Sanchez-Matamoros, Gutiérrez, Espejo e Fenech (2005) apresentam os números contábeis como mecanismos de controle do governo britânico. Ezzamel (2009) demonstra que o uso das inscrições contábeis permitiu visualizar as atividades e conquistas de vários setores da sociedade egípcia e incentivar indivíduos a demonstrar que suas ações eram consistentes com as qualidades necessárias à ordem social e econômica. Sargiacomo (2009) identificou que inscrições contábeis eram capazes de reportar qualquer má conduta dos funcionários que integrassem o aparelho de Estado e a população em geral; Silva, Rodrigues e Sangster (2019) apresentam como as inscrições contábeis permitiram ao governo brasileiro exercer controle sobre o regime de tutela dos africanos livres. Nesta pesquisa, usando o conceito da governamentalidade de Foucault, procuramos analisar o poder organizacional exercido sobre populações específicas por meio das inscrições contábeis, com o intuito de manter a ordem social no processo de transição gradual do trabalho escravo para o trabalho assalariado.

Para alcançar o objetivo proposto, este estudo realiza uma análise historiográfica por meio dos regulamentos do Fundo de Emancipação e material de arquivo localizados em bibliotecas e arquivos históricos do Brasil e dos Estados Unidos. Obras secundárias que examinaram o Fundo de Emancipação dos pontos de vista sociológico, econômico e histórico foram usadas para corroborar evidências e fornecer embasamento teórico para a análise interpretativa dos dados.

\section{CONTEXTUALIZAÇÃO}

No início do século XIX, inspirada pelo liberalismo e ideias iluministas que imperavam na Europa, a política britânica passa a combater a escravidão (Fausto, 1996). Argumentava-se que o escravismo contrariava profundamente o desenvolvimento da indústria e da produção da riqueza pública e privada (Malheiros, 1866). As fortes influências da Grã-Bretanha para a extinção do tráfico internacional foram grandes propulsoras à discussão parlamentar sobre a adoção de medidas para a proibição do desembarque e libertação de escravos no Brasil.

Com o intuito de abrandar essa pressão internacional, o governo brasileiro, em 7 de novembro de 1831, promulgou a Lei Feijó (Lei de 7 de novembro, 1831), que considerava livres todos os escravos que desembarcassem em território ou portos brasileiros. Contudo, a situação econômica do Brasil, dependente da mão de obra escrava, não foi favorável à devida e correta aplicação dessa lei. A Lei Feijó ficou conhecida na história como uma norma criada para falsear uma intenção abolicionista no Brasil e servir apenas como uma "lei para inglês ver" (Bethell, 1976).

Os esforços britânicos para o fim do tráfico de escravos continuaram e, em 1845, com o Ato Aberdeen, cruzadores da marinha britânica passaram a apreender navios brasileiros 
suspeitos de realizarem tráfico de escravos e levá-los a julgamento (Baronov, 2000; Klein \& Luna, 2009). Em resposta às diversas pressões, tanto externas como internas, no ano de 1850, o governo brasileiro, em mais uma tentativa de extinguir o tráfico de escravos, promulgou a Lei Eusébio de Queiroz (Lei n ${ }^{\circ}$ 581,1850 ), que criminalizava a atividade.

Depois de 1850, as propostas com sugestões para a emancipação dos escravos de modo gradual se intensificaram, uma vez que existia a preocupação, por parte da Câmara dos Deputados e da elite brasileira, sobre a abolição ser pensada de maneira a não causar danos à propriedade rural e à agricultura do País (Malheiros, 1866; Neves, 2014). Nessa perspectiva, em 28 de setembro de 1871, foi aprovada a Lei n. 2.040, mais conhecida como Lei do Ventre Livre (Lei no $2.040,1872$ ). Essa lei atendia à preocupação de libertar os escravos de modo gradual e emancipar todos os filhos de escravos nascidos após a data de sua promulgação.

\section{Fundo de Emancipação}

A Lei do Ventre Livre instituiu um fundo público financeiro (art. 3) que tinha como propósito se transformar em uma política pública para efetivar a emancipação gradual dos escravos (Campello, 2018). Como política pública, o Fundo de Emancipação foi disciplinado por diversos atos legislativos. Constituído por recursos financeiros, os valores arrecadados para a composição do Fundo de Emancipação eram oriundos de taxas e impostos sobre os escravos, loterias, multas e contribuições. Os valores arrecadados para esse fundo funcionaram como um subsídio do governo imperial às províncias e municípios, destinado à compensação dos senhores de escravos pela propriedade perdida (Soares, 1847). O governo, portanto, passou a mediar as relações entre escravos e senhores, retirando desses últimos o controle da alforria de seus cativos (Dauwe, 2004; Teixeira, 2014, 2016). Dessa forma, mantinham-se os direitos senhoriais em certa medida, bem como atendia-se às demandas dos escravos, ainda que parcialmente (Santana, 2018).

As discussões ao longo do século XIX em torno da libertação gradual de escravos por meio da constituição do fundo financeiro expressaram, por um lado, a preocupação com os rumos que um processo de abolição total da escravidão poderia trazer para a sociedade, para a economia e para a ordem pública do País. Isso porque uma abolição completa, sem orientação e sem o controle do Estado, poderia gerar conflitos internos na nação (Malheiros, 1866). Por outro lado, foi um dispositivo legal que contribuiu para a derrocada gradual da escravidão no
Império, uma vez que abriu a possibilidade de escravos e seus familiares disputarem a liberdade nos tribunais oitocentistas (Chalhoub, 1990).

O Fundo de Emancipação foi considerado o maior aparato burocrático emancipacionista das Américas (Santana, 2018). Sua operacionalização requereu a montagem de aparato institucional expressivo, que contava com a ação de determinados indivíduos dispersos nas unidades territoriais do Império com atribuições fixas delineadas em regulamentos. O levantamento do número de escravos existentes no Império era entendido como a atividade de arranque da estrutura burocrática do fundo, que se materializava na forma de um registro denominado "matrícula especial” (Lei no 2.040, 1872). A realização da matrícula estava sob a responsabilidade direta de agentes públicos selecionados das Mesas de Rendas, Alfândegas, Tesouraria da Fazenda, Presidência da Câmara e Províncias, Promotoria Pública, Diretoria Geral de Estatística e do Ministério de Estado dos Negócios da Agricultura, Comércio e Obras Públicas; e não públicos, como os párocos e associações. Sanções como multa e prisão poderiam ser aplicadas aos agentes pelo não cumprimento ou execução errônea das atribuições estabelecidas pelos regulamentos.

O levantamento da população escrava servia de base para o cálculo do número de escravos a serem libertos e da quantia financeira (quota) do Fundo de Emancipação destinada para cada província do Império. Após a distribuição das quotas, o presidente de cada província, com o conhecimento da estatística dos municípios e freguesias, solicitava, por edital, a constituição de uma junta classificadora por município. As juntas de classificação eram compostas hierarquicamente pelo presidente da Câmara, pelo promotor público e pelo coletor das Mesas de Rendas, responsáveis por apresentar, por ordem de direito, a lista de cativos que estavam aptos a receber liberdade pelas quotas do Fundo de Emancipação.

O Fundo de Emancipação contou com uma estrutura composta por quase 800 juntas espalhadas pelo território nacional. Essa estrutura tinha o objetivo de garantir a ordem social durante o processo de libertação gradual dos escravos, por meio da gestão dos recursos e mediando ações entre senhores, libertados e seus familiares (Santana, 2018). Durante o seu vigor, que perdurou até os momentos finais da escravidão, o Fundo de Emancipação permitiu libertar cerca de 32 mil escravos em todo o Império (Dauwe, 2004; Neves, 2014; Santana, 2018). A quantidade de verbas investidas totalizou o montante de 16.259:451\$109 (dezesseis mil e duzentos e cinquenta e nove contos, quatrocentos e cinquenta e um mil e cento e nove réis) (Santana, 2012, 2018). 


\section{REFERENCIAL TEÓRICO}

Esta seção discute as inscrições contábeis e seu alinhamento ao conceito da governamentalidade de Foucault, para a construção do cenário do estudo sobre o poder estatal exercido sobre as populações por meio das inscrições contábeis.

\section{Inscrições contábeis}

O termo “inscrições contábeis” é particularmente utilizado por historiadores da contabilidade para evitar uma limitação $a$ priori do objeto de estudo à contabilidade como ela atualmente existe (quanto ao conteúdo e formato) ou a uma técnica contábil específica, como as partidas dobradas (Miller \& Napier, 1993). Para Miller (1990), os procedimentos de inscrição auxiliam a formação dos diversos domínios da governamentalidade, pois estas permitem que "objetos", como os indivíduos, sejam materializados e se tornem passíveis de intervenção e regulamento. As inscrições funcionam como mediadoras entre o ator e os diversos cenários nos quais ele pretende atuar e que se encontram distantes (Latour, 1988).

Inscrições podem ser representadas, por exemplo, por traços, pontos, histogramas, números, tabelas (Latour \& Woolgar, 2013). Por meio dessas representações, qualquer expressão pode apresentar significado e fatos que podem ser compreendidos (Latour, 1987). Todavia, é importante destacar que nem todas as formas de cálculo são "contábeis", mas tão somente aquelas que permitem a construção e cálculo de objetos ou entidades contáveis anteriormente invisíveis (Meyer, 1986; Power, 1992). A operacionalização das inscrições contábeis prevê, ainda, a existência de uma unidade responsável de registro, na qual o objeto é reconhecido (i.e., contabilizado) por uma pessoa responsável (Jones, 2009).

As ferramentas do Estado na construção dos cenários de seu interesse são as tecnologias do governo utilizadas para intervir na população, tais como cálculos, técnicas, aparelhos, documentos e procedimentos por meio dos quais as autoridades buscam incorporar e dar efeito às ambições governamentais (Dean, 2010). De acordo com Miller (1990), as tecnologias do governo permitem uma forma de domínio intelectual, que se torna possível pela existência de um centro o qual possui informações sobre pessoas e eventos, que estão distantes daquele. Ademais, em consonância com Latour (1988), a gestão de informações sobre os fluxos populacionais para um centro é chamada de centro de cálculo (Latour, 1988).

A contabilidade gera inscrições numéricas com habilidade para criar e diminuir distâncias, por exemplo, as distâncias materiais e administrativas (Corvellec, Ek, Zapata, \& Campos, 2018). Essas inscrições são particularmente úteis no processo de vigilância por causa de sua mobilidade, estabilidade e capacidade de combinação (Latour, 1987). As inscrições contábeis são móveis, pois podem ser movidas e levar assuntos remotos para os locais onde ocorre a vigilância. São estáveis e combináveis, porque os números viajam sem mudar à medida que são movimentados pelas organizações e porque podem ser adicionados, subtraídos, divididos e multiplicados para fornecer insights relevantes e adicionais sobre um evento que se encontra distante, como a existência de erros, fraudes, arrecadação de receita, aplicação dos recursos (Andon, Baxter, \& Chua, 2003; Cuganesan, 2008; Latour, 1987). Portanto, as inscrições podem agir a distância por sua capacidade de construir relacionamentos entre elementos considerados desconectados (Corvellec et al., 2018).

Para Espejo, Sánchez-Matamoros e Fenech (2002, p. 422), a quantidade de inscrições contabilísticas desempenha um papel fundamental para controlar os indivíduos, pois, por meio da gestão da informação acumulada pelas inscrições, criam uma poderosa ferramenta de gestão para o governo.

\section{Inscrições contábeis para a governamentalidade}

Governamentalidade é uma terminologia usada para denominar o conjunto formado pelas instituições, procedimentos, análises, reflexões, cálculos e táticas utilizadas pelo governo que permitem o exercício do poder e tem como alvo a manutenção da riqueza e bem-estar da população. Ela surge como um método de análise das atitudes do governo, assumindo que este segue um caminho estrategicamente planejado (Dean, 2010).

Nesse âmbito, a análise das atitudes de intervenção do governo reside na ligação de complexos procedimentos de representação e influência (Espejo et al., 2002). Esses procedimentos, em conformidade com Foucault (1991), são trazidos à realidade como programas governamentais para atender as intenções do governo. Assim, surge 0 "caráter programático da governamentalidade", já que o governo elabora programas para reformar a realidade de acordo com seus interesses, com o objetivo de organizar as situações para que sejam alcançados certos fins (Miller, 1990; Rose \& Miller, 1992).

$\mathrm{Neu}(2000 \mathrm{a}, 2000 \mathrm{~b})$ apresenta a contabilidade como uma tecnologia usada pelo governo com o objetivo de tornar governável uma população específica. Com o uso das técnicas 
e expressões da contabilidade, o império britânico conseguiu manter centros de cálculos (local onde as informações são acumuladas) que permitiram o acompanhamento do território e da população. Além disso, também foi usada para mudar os hábitos, costumes e comportamentos da população.

Sanchez-Matamoros et al. (2005) identificaram que números contábeis serviram como mecanismos do governo para a gestão de duas empresas apoiadas com recursos governamentais, funcionando como meio para a coleta de dados sobre quanto cada trabalhador estava produzindo, sobre o número esperado de produtos, sobre a existência de furtos. Com base nas informações coletadas, o governo poderia emitir instruções formais e garantir as mudanças necessárias, na contabilidade, para a manutenção do efetivo controle.

Ao examinar o poder discursivo da contagem, dos números contábeis e das inscrições na criação e promoção da "ordem" na sociedade do antigo Egito, Ezzamel (2009) identificou o funcionamento da contabilidade como um ritual performativo que construía coerência e ordem no cosmos, na terra e no mundo subterrâneo. Os números contábeis eram frequentemente combinados com textos linguísticos e cenas pictóricas da arquitetura para produzir um discurso que possibilitava a construção e a perpetuação de mundos harmoniosos, com populações ordenadas e desempenhando papéis que lhes eram designados.

Em seu estudo sobre a contabilidade como ferramenta para a governamentalidade do Estado feudal italiano do século XVI, Sargiacomo (2009) afirma que as inscrições contábeis, por meio de sua correta gravação (e.g. em livros contábeis e não contábeis, inventários, relatórios dos oficiais de justiça), eram capazes de reportar ao governo de Parma qualquer má conduta dos funcionários que integravam o aparelho de Estado e a população em geral.

Em pesquisa desenvolvida por Silva et al. (2019), os autores apresentaram como as inscrições contábeis (e.g. mapas com números de africanos livres mortos, lista de africanos livres alugados e respectivos valores, lista de devedores e respectivos valores) permitiram ao governo brasileiro exercer controle sobre o regime de tutela dos africanos livres. Como uma ferramenta de informação e controle, a contabilidade e suas expressões permitiram a criação de registros que serviram aos interesses do Estado no que diz respeito à redução de custos com os africanos livres e ao aumento de sua receita com a arrecadação de salários dos africanos livres.

A contabilidade como tecnologia para a gestão do governo é imbuída de aspirações para moldar a conduta com a esperança de produzir certos efeitos desejados (Miller,
1990, p. 318). Portanto, percebe-se que a contabilidade e suas expressões podem desempenhar um papel fundamental como meio de controle de indivíduos, por intermédio da gestão da informação, podendo ser uma poderosa ferramenta nas mãos da entidade.

\section{METODOLOGIA}

Pesquisas recentes debatem ativamente as metodologias de pesquisa na história dos negócios (Gill, Gill, \& Roulet, 2018; Maclean, Harvey, \& Clegg, 2016, 2017) com o intuito de reconhecer a importância do passado em influenciar o presente e moldar o futuro (Carnegie \& Napier, 1996). Historicizar a contabilidade no âmbito organizacional pode sensibilizar sujeitos sobre a força e o uso de ferramentas em contextos específicos que envolvem as empresas. Indivíduos podem sentir-se motivados a se tornarem comentaristas dos desenvolvimentos e usos contemporâneos de ferramentas empresariais, como a contabilidade, tornando-se capazes de propor, inclusive, o uso da contabilidade como instrumento de mudança nas organizações e na sociedade (Gomes, Carnegie, Napier, Parker, \& West, 2011).

Para contar a história da contabilidade no âmbito organizacional, este trabalho usa o método do estudo de caso, concentrando-se no Fundo de Emancipação de escravos no Brasil. A natureza holística dessa abordagem permite que o pesquisador colete os dados por diversos meios (Diab, 2019) e, assim, possa compreender fenômenos sociais complexos (Parker, 2019). Atendendo a natureza do estudo de caso, as fontes primárias foram identificadas e coletadas na Biblioteca Nacional Digital (BNDigital), na Biblioteca Brasiliana Guita e José Mindlin (BBGJ) e no Center Research Library (CRL). Fontes próximas no tempo, internas e escritas para usos imediatos (Decker, 2013), foram combinadas com o conceito de governamentalidade de Foucault para a interpretação de narrativas históricas (Kasabov \& Sundaram, 2014), respondendo à seguinte questão de pesquisa: Como o poder organizacional pode ser exercido por meio das inscrições contábeis?

Os dados foram analisados manualmente por meio da intuição e escrutínio dos pesquisadores (Lage \& Godoy, 2008), o que contribuiu com a organização dos dados em formato de resumo e com a observação de resultados e temas anteriores (Boedker, Chong, \& Mouritsen, 2019). Ademais, para examinar as múltiplas fontes de pesquisa, nos envolvemos em: 1) críticas à fonte, nos questionando sobre cada documento encontrado; 2) 
triangulação, observando os documentos criados por diferentes atores do mesmo evento; e 3) interpretação hermenêutica, por meio do reconhecimento do contexto cultural, social e temporal da criação dos documentos e pela seleção e citação de uma pequena parte dos documentos lidos (Kipping, Wadhwani, \& Bucheli, 2014).

A análise interpretativa hermenêutica foi dividida em interpretativa de narrativas históricas e reiterativa. A análise interpretativa de narrativas históricas permitiu explicações e críticas ao evento e sujeitos em estudo (Carnegie \& Napier, 1996). 0 processo de análise interpretativa e reiterativa envolveu a combinação contínua de interpretações baseadas na literatura e reflexões sobre os dados empíricos, sob forma de apresentar um retrato de estratégias e processos inseridos no Fundo de Emancipação de escravos, com vistas a oferecer interpretações e explicações (Carr, 1986) que reconhecem as inter-relações existentes no programa.

Com o objetivo de apresentar uma síntese criativa entre o estudo da história e da organização, Maclean et al. (2016, 2017) apresentam cinco princípios: 1) dupla integridade, que tem como princípios a veracidade histórica e o rigor conceitual; 2) entendimento pluralista, que permite a compreensão por meio de alternativas e diferentes formas de ver; 3) verdade representacional, que se apoia na congruência entre evidência, lógica e interpretação; 4) sensibilidade ao contexto, que consiste na atenção do pesquisador às especificidades históricas; e 5) fluência teórica, que representa o comando do terreno conceitual. 0 presente artigo está alinhado com os princípios da dupla integridade, verdade representacional e sensibilidade ao contexto.

0 estudo também se baseia na análise de pesquisas secundárias desenvolvidas por estudiosos que nos precederam. No campo histórico sobre o Fundo de Emancipação de escravos (Dauwe, 2004; Neves, 2014; Santana, 2018), os estudos evidenciam os papéis das populações e a estrutura de um programa de governo estabelecido no ano de 1871 . No campo contabilístico sobre o uso das inscrições contábeis como tecnologia do governo (Ezzamel, 2009; Neu, 2000a, 2000b; Sanchez-Matamoros et al., 2005; Sargiacomo, 2009; Silva et al., 2019), as pesquisas apresentam as inscrições contábeis como mecanismos capazes de colocar em prática os objetivos delineados pelo Estado.

As fontes secundárias foram usadas para a definição da área temática, para corroborar evidências e para fornecer embasamento teórico (Braun \& Clarke, 2006). Os aspectos estudados, principais fontes e número de documentos estão apresentados no Quadro 1.
Quadro 1. Critérios, princípios e técnicas orientadores da pesquisa

\begin{tabular}{l|l|l}
\hline Aspectos estudados & Principais fontes & $\begin{array}{l}\text { Número de } \\
\text { documentos }\end{array}$ \\
\hline $\begin{array}{l}\text { Contexto político, } \\
\text { econômico e social }\end{array}$ & $\begin{array}{l}\text { Fontes secundárias } \\
\text { e regulamentos } \\
\text { sobre a abolição da } \\
\text { escravatura. }\end{array}$ & $\begin{array}{l}\text { (2) obras raras; } \\
\text { legislação. }\end{array}$ \\
\hline \multirow{2}{*}{ teórico } & $\begin{array}{l}\text { Artigos científicos } \\
\text { publicados em } \\
\text { revistas indexadas. }\end{array}$ & $\begin{array}{l}\text { (24) artigos } \\
\text { científicos. }\end{array}$ \\
\hline \multirow{2}{*}{ Discussão } & $\begin{array}{l}\text { Fontes secundárias; } \\
\text { regulamentos } \\
\text { sobre a abolição } \\
\text { da escravatura; } \\
\text { extratos de } \\
\text { jornais de época } \\
\text { localizados em } \\
\text { arquivo. }\end{array}$ & $\begin{array}{l}\text { (3) legislações; } \\
\text { científicos; (2) } \\
\text { notícias de jornais. }\end{array}$ \\
\hline
\end{tabular}

Fontes primárias são usadas para investigar o contexto social, político e econômico e centram-se na legislação sobre o Fundo de Emancipação que foi localizada na BBGJ. Os dados referentes à composição do Fundo de Emancipação foram identificados nos relatórios do Ministério da Fazenda, localizados no CRL. Por sua vez, informações relacionadas à distribuição das quotas do Fundo de Emancipação foram identificadas em jornais de época localizados na BNDigital.

\section{INSCRIÇÕES CONTÁBEIS NO FUNDO DE EMANCIPAÇÃO DE ESCRAVOS}

A Lei do Ventre Livre prevê um processo contabilístico dotado de três atividades distintas (i.e., registro, sumarização dos dados e elaboração de demonstrativos), define objetos e unidades contáveis, bem como atribui os atores responsáveis pela implementação do Fundo de Emancipação.

O sistema de registro idealizado pelo Estado concede visibilidade a dois objetos contáveis (i.e., o escravo e o seu senhor), cujos dados eram inscritos em livros distintos, tendo o município (parcela da divisão administrativa do território) como unidade contável. Reconhecia-se, igualmente, que o escravo poderia, após o registro inicial, deslocar-se de unidade, o que impreterivelmente ensejaria alteração na inscrição contábil originária. 0 escravo é o primeiro objeto contável referido no Decreto n. 5.135 (art. 1), cujo registro 
incluía alguns dos seus atributos (i.e., nome, sexo, cor, idade, estado civil, filiação, aptidão para o trabalho, profissão e observações relevantes) e de seu respectivo senhor (i.e., nome e residência). Esse conjunto de dados era introduzido no livro denominado Modelo A (Quadro 2), que ainda incluía quatro outras colunas destinadas à captura do dia da matrícula (i.e., registro inicial), os números de inscrição atribuídos ao escravo e ao seu senhor, e informações relevantes pós-matrícula (e.g., alforrias, mudança de município, mudança de proprietário, falecimento). 0 senhor figura aqui como contrapartida do objeto contável focal do livro (i.e., escravo). As colunas destinadas aos números de inscrição, bem como a data da matrícula, funcionavam como trilha de auditoria (Sangster, 2016), o que permitia a rastreabilidade da informação dos objetos contáveis e garantia acurácia na identificação da existência de homônimos.

\section{Quadro 2. Modelo A}

Para a escrituração do livro da matrícula especial de todos os escravos existentes no município de da província de (Artigo $1^{\circ}$ do Regulamento)

\begin{tabular}{|c|c|c|c|c|c|c|c|c|c|c|c|c|c|c|c|c|c|}
\hline \multirow{3}{*}{ 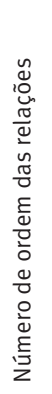 } & \multicolumn{2}{|c|}{ Senhores } & \multicolumn{5}{|c|}{ Matrícula } & \multirow{2}{*}{\multicolumn{8}{|c|}{ Escravos }} & \multirow[b]{3}{*}{ 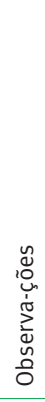 } & \\
\hline & \multirow[b]{2}{*}{$\begin{array}{l}\stackrel{0}{E} \\
\stackrel{0}{2}\end{array}$} & \multirow[b]{2}{*}{ 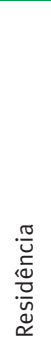 } & \multicolumn{2}{|c|}{$\begin{array}{l}\text { Número de } \\
\text { ordem }\end{array}$} & \multicolumn{3}{|c|}{ Data } & & & & & & & & & & \\
\hline & & & 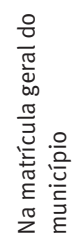 & 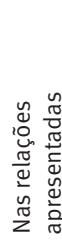 &.$\frac{\pi}{\Delta}$ & $\sum_{\Sigma}^{\infty}$ & $\stackrel{\circ}{\frac{\varepsilon}{4}}$ & 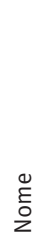 & $\stackrel{\stackrel{P}{u}}{\sim}$ & む & $\frac{\frac{0}{0}}{\frac{\pi}{0}}$ & $\begin{array}{l}\text { 유 } \\
\text { 苟 }\end{array}$ & $\begin{array}{l}\text { 㥕 } \\
\text { 尝 }\end{array}$ & 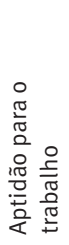 & 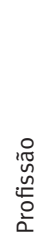 & & 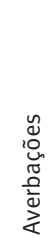 \\
\hline & & & & & & & & & & & & & & & & & \\
\hline & & & & & & & & & & & & & & & & & \\
\hline
\end{tabular}

Fonte: Adaptado de Lei ํㅜ 2.040 (1872).

O segundo objeto contável referido no Decreto n. 5.135 foi o senhor (art. 2), cujo registro (no livro denominado Modelo B) incluía tão somente seu nome, município de residência e assinatura. Todos os demais campos capturavam informações sobre seus escravos já registradas no Modelo A, com exceção da inclusão da naturalidade do escravo (ver Quadro 3). A primeira coluna à esquerda no Modelo $B$ era destinada à menção do número de inscrição geral do escravo no município, enquanto a segunda coluna seria o número de ordem na relação do senhor em questão. A assinatura do senhor no livro, ou de seu preposto, legitima a relação entre devedores e credores, fato que caracteriza o sistema contabilístico de partidas simples (Yamey, 2005).

\section{Quadro 3. Modelo B}

Relação n. 4 dos escravos pertencentes a F..., residente no município de ........

(Artigo $2^{\circ}$ do Regulamento)

\begin{tabular}{l|l|l|l|l|l|l|l|l|l}
\hline & Nome & Cor & Idade & Estado & Naturalidade & Filiação & Profissão & Observações \\
\hline & & & & & & & \\
\hline & & & & & & & & \\
\hline
\end{tabular}

Apresentado a matricula e matriculado em ..... de ...... de 1872.

Pagou

Cidade (ou vila) de .... de 1872.

o Administrador-F.....

O Escrivão-F.....

Como procurador do senhor-F.... 
O Decreto n. 5.135 ainda previa um conjunto de formalidades extrínsecas para os livros de registros da matrícula especial, como a obrigatoriedade de serem numerados, rubricados e encerrados pelo Inspetor da Tesouraria da Fazenda em cada província (art. 8). 0 termo de encerramento era lavrado posteriormente pelos funcionários responsáveis pela matrícula na presença do presidente da Câmara municipal de vereadores e do promotor público, que igualmente o assinavam (art. 15). Tais formalidades também eram obrigatórias para livros contabilísticos principais (e.g., Diário) de negociantes, conforme disciplinava o art. 13 do Código Comercial (Lei n. 556, de 25 de junho de 1850).

Ao termo do período de registro, que findava aos 30 de setembro de cada ano, os agentes públicos responsáveis deveriam sumarizar os dados coletados, utilizando-se para tal o Modelo E (Quadro 4). A disposição interna das tabelas era a ordem decrescente da quantidade de escravos de cada senhor. A adoção de tal critério pode ser justificada pela premissa de que famílias eram prioritárias na classificação para a concessão de liberdade pelo Fundo de Emancipação (art. 27 do Decreto n. 5.135, de 13 de novembro de 1872). 0 sumário ainda indicava o número e a página onde estavam os dados nos livros de registro (Modelos A e B).

\section{Quadro 4. Modelo E}

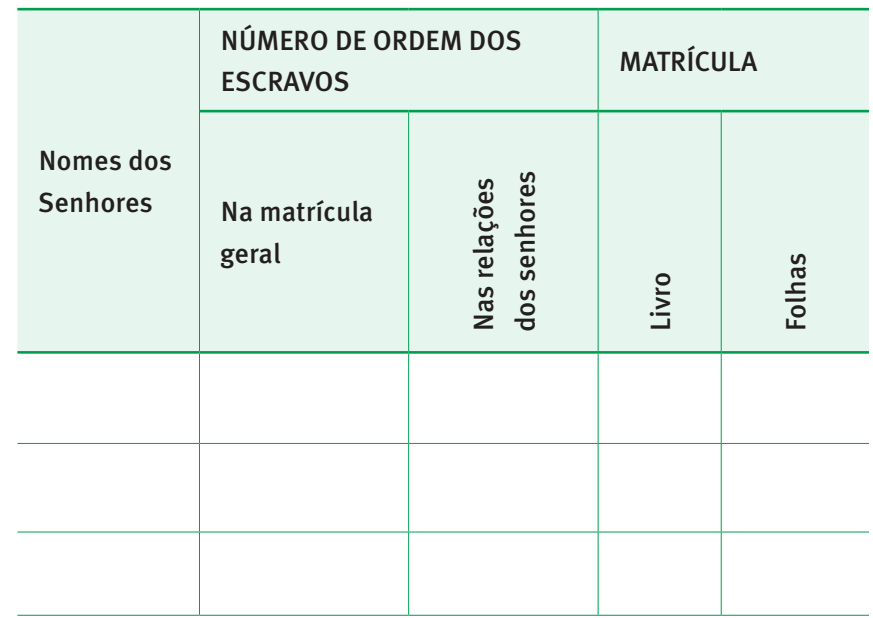

Fonte: Adaptado de Lei nํㅜ 2.040 (1872).

Após o levantamento do sumário, a informação deveria ser transmitida durante o decurso do mês de outubro à Diretoria Geral de Estatística (art. 20 do Decreto n. 5.135), órgão vinculado ao Ministério dos Negócios da Agricultura, Comércio e Obras Públicas, na corte, por meio do Resumo Geral dos Escravos Matriculados no Município definido pelo Decreto n. 5.135 (Quadro 5).

\section{Quadro 5. Modelo G}

Resumo geral dos escravos matriculados no município de .... província de .....

(Artigo 20 do Regulamento)

Desde o dia .... de .... de 1872 até o dia .... de .... do mesmo ano, matricularam-se ..... escravos, sendo:

\begin{tabular}{|c|c|}
\hline \multirow{3}{*}{ Sexo } & Masculino \\
\hline & Feminino \\
\hline & Soma \\
\hline \multirow{9}{*}{ Idade } & Até 1 ano \\
\hline & De 1 a 7 anos \\
\hline & De 7 a 14 anos \\
\hline & De 14 a 21 anos \\
\hline & De 21 a 40 anos \\
\hline & De 40 a 50 anos \\
\hline & De 50 a 60 anos \\
\hline & Maiores de 60 \\
\hline & Soma \\
\hline \multirow{4}{*}{ Estado } & Solteiros \\
\hline & Casados \\
\hline & Viúvos \\
\hline & Soma \\
\hline \multirow{4}{*}{ Profissão } & Agrícola \\
\hline & Artista \\
\hline & Jornaleiro \\
\hline & Soma \\
\hline \multirow{3}{*}{ Residência } & Urbanos \\
\hline & Rurais \\
\hline & Total \\
\hline
\end{tabular}

Fonte: Lei $n \cong 2.040$ (1872).

O governo central mantinha informações sobre os valores arrecadados para o Fundo de Emancipação por rubrica (Tabela 1) e por província (Tabela 2). 
FÓRUM | INSCRIÇÕES CONTÁBEIS PARA O EXERCÍCIO DO PODER ORGANIZACIONAL: O CASO DO FUNDO DE EMANCIPAÇÃO DE ESCRAVOS NO BRASIL

Adriana Rodrigues Silva | Angelica Vasconcelos | Thais Alves Lira

Tabela 1. Arrecadação para o Fundo de Emancipação por rubrica

\begin{tabular}{|c|c|c|c|c|}
\hline & $1871-72$ & $1872-73$ & $1873-74$ & Total \\
\hline Transmissão de propriedade dos ditos & $66.410 \$ 325$ & $103.287 \$ 176$ & $150.837 \$ 648$ & $320.535 \$ 149$ \\
\hline Idem por doação & $554 \$ 082$ & $2.350 \$ 858$ & $919 \$ 450$ & $3.824 \$ 390$ \\
\hline Emolumentos de matrículas & $215.928 \$ 500$ & $501.415 \$ 500$ & $37.771 \$ 000$ & $755.115 \$ 000$ \\
\hline Multas & $1.076 \$ 000$ & $26.580 \$ 000$ & $18.250 \$ 000$ & $45 \cdot 906 \$ 000$ \\
\hline Donativos & $1.261 \$ 213$ & $460 \$ 592$ & $525 \$ 741$ & $2.247 \$ 546$ \\
\hline Benefício de loterias isentas de impostos & $129.600 \$ 000$ & $213.600 \$ 000$ & $214 \cdot 500 \$ 000$ & $557.700 \$ 000$ \\
\hline Cobrança da dívida activa & o & $3 \cdot 344 \$ 000$ & $44 \$ 000$ & $3 \cdot 388 \$ 000$ \\
\hline
\end{tabular}

Fonte: Ministério da Fazenda (1874).

Tabela 2. Arrecadação para o Fundo de Emancipação por Província

\begin{tabular}{|c|c|c|c|c|}
\hline & $1871-72$ & $1872-73$ & $1873-74$ & Total \\
\hline Município & $447.417 \$ 325$ & $564.774 \$ 176$ & $544.835 \$ 728$ & $1.557 .027 \$ 229$ \\
\hline Rio de Janeiro & $93.166 \$ 710$ & $153.028 \$ 907$ & $35.874 \$ 441$ & $282.070 \$ 058$ \\
\hline Espírito Santo & $7.822 \$ 000$ & $10.168 \$ 500$ & $2.497 \$ 500$ & $20.488 \$ 000$ \\
\hline Bahia & $84.768 \$ 240$ & $122.895 \$ 802$ & $23.318 \$ 000$ & $230.982 \$ 042$ \\
\hline Sergipe & $17.631 \$ 840$ & $15.483 \$ 768$ & $3.110 \$ 970$ & $36.226 \$ 578$ \\
\hline Alagoas & $18.129 \$ 920$ & $21.830 \$ 383$ & $886 \$ 890$ & $40.847 \$ 193$ \\
\hline Pernambuco & $60.972 \$ 500$ & $75.152 \$ 200$ & $31.192 \$ 650$ & $167.317 \$ 350$ \\
\hline Parahiba & $8.060 \$ 320$ & $10.866 \$ 500$ & $700 \$ 940$ & $19.627 \$ 760$ \\
\hline Rio Grande do Norte & $4.260 \$ 250$ & $6.330 \$ 130$ & $1.354 \$ 240$ & $11.944 \$ 620$ \\
\hline Ceará & $14.741 \$ 070$ & $22.882 \$ 990$ & $6.118 \$ 460$ & $43.742 \$ 520$ \\
\hline Piauhy & $9.446 \$ 130$ & $11.952 \$ 080$ & $348 \$ 280$ & $21.746 \$ 490$ \\
\hline Maranhão & $48.745 \$ 050$ & $41.600 \$ 760$ & $13.296 \$ 050$ & $103.641 \$ 860$ \\
\hline Pará & $25.954 \$ 113$ & $20.547 \$ 940$ & $13.662 \$ 140$ & $60.164 \$ 193$ \\
\hline Amazonas & $1.263 \$ 060$ & $1.164 \$ 220$ & $108 \$ 730$ & $2.536 \$ 010$ \\
\hline São Paulo & $40.766 \$ 082$ & $128.207 \$ 245$ & $6.849 \$ 140$ & $175.822 \$ 467$ \\
\hline Paraná & $8.858 \$ 240$ & $11.543 \$ 120$ & $2.025 \$ 650$ & $22.427 \$ 010$ \\
\hline Santa Catharina & $11.172 \$ 880$ & $13.226 \$ 030$ & $1.624 \$ 000$ & $26.022 \$ 910$ \\
\hline São Pedro & $53.082 \$ 980$ & $75.285 \$ 590$ & $17.747 \$ 840$ & $146.116 \$ 410$ \\
\hline Minas & $86.838 \$ 190$ & $152.892 \$ 000$ & $17.369 \$ 500$ & $257.099 \$ 690$ \\
\hline Goyaz & $3.204 \$ 000$ & $6.408 \$ 400$ & $318 \$ 000$ & $9.930 \$ 400$ \\
\hline \multirow[t]{2}{*}{ Mato Grosso } & $3.884 \$ 500$ & $3.201 \$ 520$ & $333 \$ 000$ & $7.419 \$ 020$ \\
\hline & $1.050 .185 \$ 400$ & $1.469 .442 \$ 261$ & $723.572 \$ 149$ & $3.243 .199 \$ 810$ \\
\hline
\end{tabular}

Fonte: Ministério da Fazenda (1874). 
FÓRUM | INSCRIÇÕES CONTÁBEIS PARA O EXERCÍCIO DO PODER ORGANIZACIONAL: O CASO DO FUNDO DE EMANCIPAÇÃO DE ESCRAVOS NO BRASIL

Adriana Rodrigues Silva | Angelica Vasconcelos | Thais Alves Lira

0 art. 25 do Decreto n. 5.135 , de 13 de novembro de 1872 , estabeleceu que “o Fundo de Emancipação deveria ser distribuído anualmente para o município neutro e para as províncias do Império na proporção da respectiva população escrava", como se observa na Tabela 3.

\section{Tabela 3. Quotas do Fundo de Emancipação distribuídas} pelas províncias

\begin{tabular}{|c|c|c|}
\hline \multicolumn{3}{|c|}{ Segunda distribuição do Fundo de Emancipação } \\
\hline Província & Escravos & Quotas \\
\hline Corte & 43.409 & $142.782 \$ 638$ \\
\hline Rio de Janeiro & 289.239 & $951.376 \$ 620$ \\
\hline Pernambuco & 91.992 & $302.583 \$ 808$ \\
\hline Maranhão & 63.164 & $207.761 \$ 584$ \\
\hline Amazonas & 974 & $3.203 \$ 720$ \\
\hline Pará & 30.623 & $100.726 \$ 410$ \\
\hline Rio Grande do Sul & 75.973 & $294.775 \$ 052$ \\
\hline Sergipe & 26.381 & $86.773 \$ 452$ \\
\hline Santa Catarina & 12.889 & $42.197 \$ 665$ \\
\hline Rio Grande do Norte & 10.128 & $33.819 \$ 970$ \\
\hline Piauhy & 21.216 & $69.784 \$ 530$ \\
\hline Espírito Santo & 21.216 & $69.784 \$ 530$ \\
\hline Alagoas & 30.597 & $99.983 \$ 042$ \\
\hline Paraná & 10.088 & $33.181 \$ 857$ \\
\hline Mato Grosso & 7.051 & $23.192 \$ 434$ \\
\hline São Paulo & 108.950 & $555.717 \$ 175$ \\
\hline Bahia & 116.108 & $381.907 \$ 130$ \\
\hline Minas Gerais & 289.919 & $953.613 \$ 303$ \\
\hline Goyaz & 6.963 & $22.902 \$ 981$ \\
\hline Parahyba & 25.596 & $84.191 \$ 398$ \\
\hline Ceará & 25.773 & $84.740 \$ 701$ \\
\hline Somma & 1.368 .097 & $4.500 .000 \$ 000$ \\
\hline
\end{tabular}

Fonte: Pinheiro (1880).

Após a distribuição das quotas do Fundo de Emancipação para as províncias, o governo provincial, em comunicado ao inspetor da Tesouraria da Fazenda, solicitava um quadro-resumo (Tabela 4), no qual constasse o número de escravos existente em cada um dos municípios, a fim de proceder-se a distribuição das quotas.

\section{Tabela 4. Quotas do Fundo de Emancipação distribuídas pelos 38 municípios do estado do Pará}

Quadro demonstrativo das quotas do fundo de emancipação distribuídas pelos 38 municipios da provincia do Pará, por portaria da presidencia de 9 de dezembro de 1876

\begin{tabular}{|c|c|c|}
\hline Municípios & Escravos & Quotas \\
\hline Capital & 4.046 & $2.800 \$ 504$ \\
\hline Mojú & 607 & $969 \$ 000$ \\
\hline Igarapé Miry & 4.017 & $2.800 \$ 000$ \\
\hline Ourem & 228 & $937 \$ 000$ \\
\hline Cametá & 2.859 & $2.000 \$ 000$ \\
\hline Barão & 141 & $911 \$ 000$ \\
\hline Breves & 557 & $959 \$ 000$ \\
\hline Melgaço & 70 & $861 \$ 000$ \\
\hline Portel & 68 & $861 \$ 000$ \\
\hline Oueiras & 48 & $811 \$ 000$ \\
\hline Curralinho & 165 & $925 \$ 000$ \\
\hline Cachoeira & 529 & $959 \$ 000$ \\
\hline Muaná & 612 & $969 \$ 000$ \\
\hline Monsarás & 175 & $911 \$ 000$ \\
\hline Soure & 364 & $949 \$ 000$ \\
\hline Chaves & 644 & $969 \$ 000$ \\
\hline Gurupá & 351 & $949 \$ 000$ \\
\hline Macapá & 542 & $959 \$ 000$ \\
\hline Mazagão & 21 & $811 \$ 000$ \\
\hline Santarém & 1156 & $1.811 \$ 000$ \\
\hline Monte Alegre & 274 & $939 \$ 000$ \\
\hline óbidos & 1138 & $1.811 \$ 000$ \\
\hline Vila Franca & 88 & $861 \$ 000$ \\
\hline Alemquer & 313 & $949 \$ 000$ \\
\hline Faro & 76 & $861 \$ 000$ \\
\hline Vigia & 747 & $1.000 \$ 000$ \\
\hline Cintra & 210 & $939 \$ 000$ \\
\hline Curuçá & 379 & $949 \$ 000$ \\
\hline Bragança & 640 & $979 \$ 000$ \\
\hline Vizeu & 190 & $911 \$ 000$ \\
\hline Porto de Moz & 111 & $911 \$ 000$ \\
\hline Itaituba & 30 & $811 \$ 000$ \\
\hline São Sebastião da Boa Vista & 174 & $911 \$ 000$ \\
\hline S. Miguel & 344 & $949 \$ 000$ \\
\hline Mocajuba & 30 & $811 \$ 000$ \\
\hline S. Caetano de Odivellas & 30 & $811 \$ 000$ \\
\hline Souzel & 30 & $811 \$ 000$ \\
\hline Acará & 920 & $1.100 \$ 000$ \\
\hline Somma & 22.924 & $41.435 \$ 504$ \\
\hline
\end{tabular}

Fonte: Mello (1876). 
Essa distribuição era possível por meio da análise dos relatórios de matrícula e de recursos arrecadados, que eram repassados ao governo central pelos encarregados por sua elaboração.

\section{ANÁLISE DOS ACHADOS}

Os dados demonstram que os quadros e tabelas podem agir a distância porque constroem relacionamentos entre elementos que são considerados desanexados (Corvellec et al., 2018). No caso do Fundo de Emancipação, a contabilidade confere visibilidade entre os objetos contáveis e o governo brasileiro, tornando-os conhecíveis por meio da criação de imagens (Quadros de 1 a 4).

A elaboração dos Quadros de 1 a 4 institui padrões de visibilidade que envolvem padrões de proximidade dos proprietários com os seus escravos e com o contexto social da época. A elaboração dos quadros direcionados à matrícula dos escravos faz com que os proprietários tomem conhecimento sobre despesas a serem pagas sobre o número de escravos que possuem, uma vez que a legislação direcionada ao Fundo de Emancipação exige o pagamento de emolumentos sobre a matrícula dos escravos. Além disso, ao registrar os escravos por meio de uma sequência preestabelecida pela legislação aplicada ao Fundo de Emancipação, as inscrições contábeis apresentam a ordem de liberdade dos escravos aos seus proprietários e, uma vez que a mão de obra deveria ser substituída, mostra também se o impacto nos seus negócios será de curto, médio ou longo prazo. Na perspectiva dos escravos, os quadros apresentam informações acerca da sua mudança de condição, ou seja, o tempo e recursos necessários para alcançar a sua liberdade.

Quando os Quadros de 1 a 4 chegam ao governo, instituem-se novos padrões de visibilidade que envolvem relações de proximidade entre os objetos contáveis e os recursos do Fundo de Emancipação de escravos. Os quadros, juntamente com o conhecimento da estatística dos municípios e freguesias sobre a população escrava, esclarecem para o governo o número de escravos em posse de cada senhor e o correto número de escravos que deveria estar registrado nos quadros elaborados. 0 governo consegue saber sobre a aplicação futura dos recursos do Fundo de Emancipação.

Por meio das Tabelas de 2 a 5 , constata-se que os eventos relacionados com a arrecadação das províncias eram mobilizados e acumulados no governo imperial, onde podiam ser "conhecidos, agregados, comparados, compilados e calculados” (Miller, 1991, p. 736). Esse centro de cálculo permitia que a distribuição das quotas do Fundo de Emancipação fosse realizada em conformidade com o número de escravos de cada província. Isso porque, com a estatística de todos os escravos e a acumulação de informações recolhidas por meio dos Quadros de 1 a 4, o governo poderia ter 0 controle sobre a quantidade de escravos existentes no Império e identificar ações necessárias para controlar os objetos contáveis e manter a ordem social (Ezzamel, 2009; Sanchez-Matamoros et al., 2005).

Os quadros e tabelas, vistos como inscrições (Latour \& Woolgar, 2013), criam relacionamentos que permitem que o conhecimento sobre os objetos contáveis anteriormente invisíveis (Meyer, 1986; Power, 1992) chegue mais longe e seja analisado em paralelo com os recursos arrecadados para o Fundo de Emancipação. Percebe-se, no mecanismo do Fundo de Emancipação, a capacidade das inscrições de agir a distância e criar novas relações espaciais de poder (Corvellec et al., 2018).

Ao obter informações sobre o número de escravos matriculados e o montante de recursos arrecadados por cada província do Império, o governo central era capaz de, por exemplo, confrontar a rubrica referente às multas com o número de matrículas realizadas fora do prazo e que constavam no livro de matrículas. Por meio dessa observação, o governo central estava apto a saber, por exemplo, se o montante arrecadado com multas correspondia ao montante que deveria ser arrecadado em sequência das matrículas atrasadas. A estrutura textual dos quadros e tabelas permitiu que a relação entre dinheiro e a mudança social do trabalho escravo para o trabalho assalariado se tornasse uma questão de rastreabilidade da informação (Sangster, 2016). Utilizava-se a rastreabilidade da informação para criar uma passagem clara e legível de uma mudança econômica e social.

Os modelos de quadros e tabelas produzidos pelas juntas de emancipação combinam a racionalidade econômica do gerenciamento com a racionalidade de uma mudança sociocultural, de modo a servir aos interesses do Estado (Silva et al., 2019) como mecanismo para a governamentalidade (Foucault, 1991) e para traduzir políticas vinculadas às mudanças sociais.

Em consonância com Sargiacomo (2009), os resultados deste estudo demonstram que a legislação, representada pela Lei do Ventre Livre e pelo Decreto n. 5.135, exigiu a formação de uma rede de prestação de contas composta por funcionários jurídicos e civis, a fim de garantir o fluxo das inscrições contábeis (Robson, 1992) das diferentes Províncias até o Ministério dos Negócios da Agricultura, Comércio e Obras Públicas. Esse fluxo das inscrições contábeis permitiu não apenas o controle da arrecadação de quantias para a constituição das quotas municipais, mas também a supervisão dos senhores quanto à realização das matrículas 
de seus escravos, o controle territorial e a governabilidade dos escravos, estabelecendo uma seleção para a alforria daqueles que seriam considerados “dignos de liberdade" e mantendo o controle do Estado sobre a transição gradual do trabalho escravo para o trabalho assalariado.

\section{CONCLUSÃO}

0 ato de traduzir as políticas governamentais em prática pode ser realizado de inúmeras maneiras. Este estudo argumentou que a contabilidade - amplamente definida como um conjunto de procedimentos, análises, reflexões, cálculos, táticas, registros, práticas de conciliação e relatórios - foi usada pelo governo imperial brasileiro na tentativa de incitar ações que facilitassem a meta de formar grupos de pessoas governáveis e, assim, operacionalizar a abolição da escravatura de modo gradual, não causando danos à sociedade (Malheiros, 1866; Neves, 2014). 0 contexto econômico e social brasileiro do século XIX passava por mudanças, e o governo procurou tornar o cidadão brasileiro flexível, ou seja, apto para fazer escolhas.

A premissa desta pesquisa é que as políticas governamentais direcionadas à população escrava do Brasil no século XIX foram realizadas por intermédio de mecanismos de contabilidade e financiamento que impactaram diretamente a população escrava e o contexto econômico e social brasileiro (Silva et al., 2019). Essas políticas governamentais também puderam ser alcançadas por meio de incentivos de outros agentes e instituições que foram capazes de empreender ações aptas a gerar impacto na população escrava. Por exemplo, atividades sutis como a prestação de contas (Sargiacomo, 2009) relativa à quantidade de escravos libertados por meio do Fundo de Emancipação contribuíram com o governo no processo de controle da libertação gradual dos escravos.

Convém destacar, por intermédio do uso do conceito da governamentalidade, que este artigo contribui para a literatura da história da contabilidade centrada no uso das inscrições contábeis para a governamentalidade (Ezzamel, 2009; Neu. 2000a, 200ob; Sanchez-Matamoros et al., 2005; Sargiacomo, 2009; Silva et al., 2019). Reforça também o papel da contabilidade como uma ferramenta de apoio para governar eventos e pessoas, mostrando que a acumulação de informações, por meio das inscrições contábeis (Robson, 1992; Ezzamel, 2009; Ezzamel et al., 2004), é capaz de contribuir com as ações do Estado no cumprimento dos seus objetivos. Ademais, este estudo também contribui com a área da história (Dauwe, 2004; Neves, 2014; Santana, 2018) que, no âmbito do Fundo de Emancipação de escravos, compreende como o poder estatal foi exercido sobre populações específicas por meio das inscrições contábeis. Por fim, espera-se sensibilizar sujeitos sobre a força e o uso de ferramentas organizacionais. Deseja-se que esses sujeitos se tornem críticos dos desenvolvimentos e usos contemporâneos de ferramentas empresariais, como a contabilidade.

Dadas a importância e a escassez de pesquisas relacionadas à contabilidade e suas expressões como mecanismos de apoio ao sistema escravista, como também para a transição do trabalho escravo para o trabalho assalariado, espera-se que os resultados deste estudo possam desafiar novas investigações centradas no Brasil e a partir da diversidade de enfoques (contábil, administrativo, econômico e histórico). Os pesquisadores críticos/ interpretativos também podem usar o arcabouço teórico utilizado neste artigo para analisar programas de governo contemporâneos que procuram direcionar a sociedade para mudanças graduais de aceitabilidade, por exemplo, programas direcionados às classes marginalizadas, como negros e indígenas.

\section{REFERÊNCIAS}

Andon, P., Baxter, J., \& Chua, W. F. (2003). Management accounting inscriptions and the post-industrial experience of organizational control. In A. Bhimani (Ed.), Management accounting in the digital economy. Oxford, UK: Oxford University Press.

Baronov, D. (2000). The abolition of slavery in Brazil: The "liberation" of Africans through the emancipation of capital ( $17^{\text {th }}$ ed.). London, UK: Greenwood Press.

Bethell, L. (1976). A abolição do tráfico de escravos no Brasil, 18071869. Rio de Janeiro, RJ: Expressão Cultural.

Boedker, C., Chong, K.-M., \& Mouritsen, J. (2019). The counterperformativity of calculative practices: Mobilising rankings of intellectual capital. Critical Perspectives on Accounting. Advanced online publications. doi: 10.1016/j.cpa.2019.102100

Braun, V., \& Clarke, V. (2006). Using thematic analysis in psychology. Qualitative research in psychology, 3(2), 77-101. doi: 10.1191/1478088706qpo630a

Campello, A. B. (2018). Manual jurídico da escravidão: Império do Brasil. São Paulo, SP: Paco Editorial.

Carmona, S. (2017). Accounting history research: Scope, topics and agenda. Revista Contabilidade \& Finanças, 28(75), 321-325. doi: 10.1590/1808-057X201790210

Carnegie, G. D., \& Napier, C. J. (1996). Critical and interpretive histories: Insights into accounting's present and future through its past. Accounting, Auditing \& Accountability Journal, 9(3), 7-39. doi: 10.1108/09513579610121956

Carr, D. (1986). Narrative and the real world: An argument for continuity. History and Theory, 25(2), 117-131. doi: 10.2307/2505301

Chalhoub, S. (1990). Visões da liberdade: Uma história das últimas décadas da escravidão na Corte. São Paulo, SP: Companhia das Letras. 
Corvellec, H., Ek, R., Zapata, P., \& Campos, M. J. Z. (2018). Acting on distances: A topology of accounting inscriptions. Accounting, Organizations and Society, 67, 56-65. doi: 10.1016/j.aos.2016.02.005

Cuganesan, S. (2008). Calculating customer intimacy: Accounting numbers in a sales and marketing department. Accounting, Auditing \& Accountability Journal, 21(1), 78-103. doi: 10.1108/09513570810842331

Dauwe, F. (2004). A libertação gradual e a saída viável: Os múltiplos sentidos da liberdade pelo fundo de emancipação de escravos (Tese de doutorado, Universidade Federal Fluminense). Recuperado de http://www.historia.uff.br/stricto/td/456.pdf

Dean, M. (2010). Governmentality: Power and rule in modern society (2nd ed.). London, UK: SAGE.

Decker, S. (2013). The silence of the archives: Business history, postcolonialism and archival ethnography. Management \& Organizational History, 8(2), 155-173. doi: 10.1080/17449359.2012.761491

Decreto $n^{0}$ 5. 135 de 13 de novembro de 1872 (1872). Coleção de Leis do Império do Brasil. Rio de Janeiro, RJ: Typographia Nacional.

Diab, A. A. (2019). The appearance of community logics in management accounting and control: Evidence from an Egyptian sugar beet village. Critical Perspectives on Accounting. doi:10.1016/j.cpa.2019.04.005

Espejo, C. Á. D., Sánchez-Matamoros, J. B., \& Fenech, F. C. (2002). Accounting and control in the founding of the New Settlements of Sierra Morena and Andalucia, 1767-72. European Accounting Review, 11(2), 419-439. doi: 10.1080/09638180220145678

Ezzamel, M. (2009). Order and accounting as a performative ritual: Evidence from ancient Egypt. Accounting, Organizations and Society, 34(3-4), 348-380. doi: 10.1016/j.aos.2008.07.004

Ezzamel, M., Lilley, S., \& Willmott, H. (2004). Accounting representation and the road to commercial salvation. Accounting, Organizations and Society, 29(8), 783-813. doi: 10.1016/j.aos.2003.10.004

Fausto, B. A. (1996). História do Brasil (12 ${ }^{\text {a }}$ ed.). São Paulo, SP: Universidade de São Paulo.

Foucault, M. (1991). Governmentality. In G. Burchell, C. Gordon, \& P. Miller (Eds.), The Foucault effect: Studies in governmentality (pp. 87104). Chicago, USA: The University of Chicago Press.

Gill, M. J., Gill, D. J., \& Roulet, T. J. (2018). Constructing trustworthy historical narratives: Criteria, principles and techniques. British Journal of Management, 29(1), 191-205. doi: 10.1111/1467-8551.12262

Gomes, D., Carnegie, G. D., Napier, C. J., Parker, L. D., \& West, B. (2011). Does accounting history matter? Accounting History, 16(4), 389-402. doi: $10.1177 / 1032373211417993$

Jones, M. J. (2009). Origins of medieval Exchequer accounting. Accounting, Business and Financial History, 19(3), 259-285. doi: 10.1080/09585200802667147

Kasabov, E., \& Sundaram, U. (2014) An institutional account of governance structures in early modern business history: The Coventry business (hi)story. Business History, 56(4), 592-622. doi: 10.1080/00076791.2013.837888

Kipping, M., Wadhwani, R. D., \& Bucheli, M. (2014). Analyzing and interpreting historical sources: A basic methodology. In M. Bucheli \& R. D. Wadhwani (Ed.), Organizations in Time: History, Theory, Methods. (pp. 305-329). Oxford, UK: Oxford University Press.
Klein, H. S., \& Luna, F. V. (2009). Slavery in Brazil. Cambridge, UK: Cambridge University Press.

Lage, M. C., \& Godoy, A. S. (2008). O uso do computador na análise de dados qualitativos: Questões emergentes. Revista de Administração Mackenzie, 9(4), 75-98. doi: 10.1590/S1678-69712008000400006

Latour, B. A. (1987). Science in action (1st ed.). Cambridge, UK: Harvard University Press.

Latour, B. A. (1988). Relativistic account of Einstein's relativity: Social studies of science (18th ed.). London, UK: SAGE.

Latour, B. A., \& Woolgar, S. (2013). Laboratory life: The construction of scientific facts. New Jersey, USA: Princeton University Press.

Lei de 7 de novembro de 1831. (1831). Declara livres todos os escravos vindos de fora do Império, e impõe penas aos importadores dos mesmos escravos. Coleção de Leis do Império do Brasil. Rio de Janeiro, RJ: Typographia Nacional.

Lei $n^{0}$ 556, de 25 de junho de 1850 (1850). Codigo Commercial do Imperio do Brasil. Coleção das Leis do Império do Brasil, vol. 1, parte 1. Rio de Janeiro: Typographia Nacional.

Lei $n^{0}$ 581, de 4 de setembro de 1850. (1850). Estabelece medidas para a repressão do tráfico de africanos neste Império. Coleção de Leis do Império do Brasil. Rio de Janeiro, RJ: Typographia Nacional.

Lei $n^{\circ} 2.040$, de 28 de setembro de 1871. (1872). Sobre o estado servil e decretos regulando a sua execução. São Paulo, SP: Typ. Americana. Recuperado de https://digital.bbm.usp.br/handle/bbm/4223

Maclean, M., Harvey, C., \& Clegg, S.R. (2016). Conceptualizing historical organization studies. Academy of Management Review, 41, 609-632. doi: 10.5465/amr.2014.0133

Maclean, M., Harvey, C., \& Clegg, S.R. (2017). Organization theory in business and management history: Current status and future prospects. Business History Review, 91, 457-481. doi: 10.1017/ So007680517001027

Malheiros, A. M. P. (1866). A escravidão no Brasil ensaio históricojurídico-social. Rio de Janeiro, RJ: Centro Edelstein de Pesquisas Sociais.

Mello, M. L., Filho. (1876, dezembro 15). Expediente do Governo. Jornal do Pará: Órgão official. Recuperado de http://memoria.bn.br/ DocReader/219339/10117

Meyer, J. W. (1986). Social environments and organizational accounting. Accounting, Organizations and Society, 11(4/5), 345-356. doi: 10.1016/0361-3682(86)90006-1

Miller, P. (1990). On the interrelations between accounting and the state. Accounting, Organizations and Society, 15(4), 315-338. doi: 10.1016/0361-3682(90)90022-M

Miller, P. (1991). Accounting innovation beyond the enterprise: Problematizing investment decisions and programming economic growth in the U.K. in the 1960s. Accounting, Organizations and Society, 16(8), 733-762. doi: 10.1016/0361-3682(91)90022-7

Miller, P., \& Napier, C. J. (1993). Genealogies of calculation. Accounting, Organizations and Society, 18(7/8), 631-647. doi: 10.1016/03613682(93)90047-A

Neu, D. (2000a). Accounting and accountability relations: Colonization, genocide and Canada's first nations. Accounting, Auditing \& Accountability Journal, 13(3), 268-288. doi: 10.1108/09513570010334126 
Neu, D. (2000b). Presents for the Indians: Land, colonialism and accounting in Canada. Accounting, Organizations and Society, 25(2), 163-184. doi: 10.1016/s0361-3682(99)00030-6

Ministério da Fazenda. (1874). Proposta e relatório apresentados à As. semblea Geral Legislativa na terceira sessão da décima quinta legislatura pelo ministro e secretário de estado dos negócios da fazenda, Visconde do Rio Branco. Rio de Janeiro, RJ: Typographia Nacional. Recuperado de http://ddsnext.crl.edu/titles/106\#? $c=0 \& m=52 \& s=0 \&$ $C V=191 \& r=0 \& x y w h=75 \% 2 C_{1501} \%_{2} C_{2} 651 \% 2 C_{14} 45$.

Neves, P. M. (2014). Liberdade sem sustos, nem inquietações: Significados e sentidos do fundo de emancipação no Grão-Pará (1871-1888) (Dissertação de mestrado, Universidade Federal do Pará). Recuperado de http://repositorio.ufpa.br/jspui/handle/2011/6755

Parker, L. D. (2019). Qualitative management accounting research: Assessing deliverables and relevance. Critical Perspective on Accounting, 23(1), 54-70. doi: 10.1016/j.cpa.2011.06.002

Pinheiro, J. P. X. (1880, junho 20). Fundo de Emancipação. Publicador Maranhense. Recuperado de http://memoria.bn.br/ docreader/720089/28866

Power, M. (1992). After calculation? Reflections on critique of economic reason by André Gorz. Accounting, Organizations and Society, 17(5), 477-499. doi: 10.1016/0361-3682(92)90043-R

Robson, K. (1992). Accounting numbers as "inscription": Action at a distance and the development of accounting. Accounting, Organizations and Society, 17(7), 685-708. doi: 10.1016/03613682(92)90019-0

Rose, N., \& Miller, P. (1992). Political power beyond the State: Problematics of government. The British Journal of Sociology, 43(2), 173-205. doi: 10.2307/591464

Sanchez-Matamoros, J. B., Gutiérrez, F., Espejo, C. Á. D., \& Fenech, F. C. (2005). Govern (mentality) and accounting: The influence of different enlightenment discourses in two spanish cases (1761-1777). ABACUS, 41(2), 181-210. doi: 10.4324/9781315164724
Sangster, A. (2016). The genesis of double entry bookkeeping. Accounting Review, 91(1), 299-315. doi: 10.2308/accr-51115

Santana, J. P., Neto. (2012). A alforria nos termos e limites da lei: O fundo de emancipação na Bahia (1871-1888) (Tese de doutorado, Faculdade de Filosofia e Ciências Humanas, Universidade Federal da Bahia, Salvador, BA). Recuperado de http://repositorio.ufba.br/ri/ handle/ri/11621

Santana, J. P., Neto. (2018). Sociedade, indenização e liberdade precária: Os meandros burocráticos do fundo de emancipação de escravos (São Francisco do Conde-BA) (Tese de doutorado, Instituto de Filosofia e Ciências Humanas, Universidade Estadual de Campinas, Campinas, SP). Recuperado de http://repositorio.unicamp.br/jspui/ handle/REPOSIP/332226

Sargiacomo, M. (2009). Accounting for the "good administration of justice": The Farnese State of Abruzzo in the sixteenth century. Accounting History, 14(3), 235-267. doi: 10.1177/1032373209335290

Soares, C. A. (1847). Memória para melhorar a sorte de nossos escravos. Rio de Janeiro, RJ: Typ. Imparcial de Francisco de Paula Brito. Recuperado de https://digital.bbm.usp.br/handle/bbm/4499

Silva, A. R., Rodrigues, L. L., \& Sangster, A. (2019). Accounting as a tool of State governance: The tutelage system of 'Free Africans' in Brazil between 1818 and 1864. Accounting History, 24(3), 383-401. doi: $10.1177 / 1032373218809519$

Teixeira, H. M. (2014). Entre a escravidão e a liberdade: As alforrias em Mariana-MG no século XIX (1840-1888). Afro-Ásia, 50, 45-92. doi: 10.1590/0002-05912014V5ohel45

Teixeira, H. M. (2016). Pelos serviços prestados: 0 perfil do escravo alforriado em Mariana no período 1840-1888. Estudos Econômicos (São Paulo), 46(1), 127-159. doi: 10.1590/0101-416146114hmt

Yamey, B. S. (2005). The historical significance of double-entry bookkeeping: Some non-Sombartian claims. Accounting, Business \& Financial History, 15(1), 77-88. doi: 10.1080/09585200500033089

\section{CONTRIBUIÇÃO DAS AUTORAS}

A conceituação e a abordagem teórico-metodológica foram coordenadas por Adriana Rodrigues Silva. A revisão teórica (pesquisa bibliográfica) foi executada por Adriana Rodrigues Silva, Angélica Vasconcelos e Thaís Alves Lira. A coleta de dados foi realizada por Adriana Rodrigues Silva, Angélica Vasconcelos e Thaís Alves Lira. Por fim, a análise dos dados, redação e revisão final foram realizadas por Adriana Rodrigues Silva e Angélica Vasconcelos. 